Critical review

\title{
XPS for chemical- and charge-sensitive analyses
}

\author{
Hikmet Sezen, Sefik Suzer * \\ Bilkent University, Chemistry Department, 06800 Ankara, Turkey
}

\section{A R T I C L E I N F O}

Available online 13 February 2013

\section{Keywords:}

Electrets

XPS

Charging

Photovoltage

Photoconductivity

Band-Bending

p-n Junction

\begin{abstract}
A B S T R A C T
By recording X-ray photoelectron spectroscopic binding energy shifts, while subjecting samples to a variety of optical and electrical stimuli, information about charge accumulation on materials or surface structures can be obtained. These stimuli included d.c. as well as a.c. electrical and/or optical pulses covering a wide frequency range $\left(10^{-3}\right.$ to $10^{6} \mathrm{~Hz}$ ) for probing charging and/or photovoltage shifts, stemming from impurities, dopants, defects, etc., whether created intentionally or not. The methodology is simple to implement and provides several new dimensions for thin films and materials analyses.
\end{abstract}

(c) 2013 Elsevier B.V. All rights reserved.

\section{Contents}

1. Introduction . . . . . . . . . . . . . . . . . . . . . . . . . . . . . . . . . . . . . . . . . . . . . . . . . . . 1

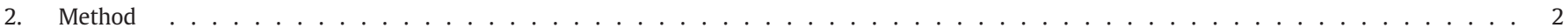

3. Materials and equipment used . . . . . . . . . . . . . . . . . . . . . . . . . . . . . . . . . . . . . . . . . . . 3

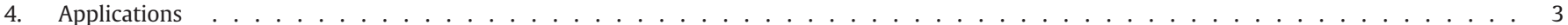

4.1. Application of external bias voltage . . . . . . . . . . . . . . . . . . . . . . . . . . . . . . . . . . . . . 3

4.2. Charges on semiconductors and band-bending . . . . . . . . . . . . . . . . . . . . . . . . . . . . . . . . . 3

4.3. $\mathrm{Si} / \mathrm{SiO}_{2}$ interfacial charges . . . . . . . . . . . . . . . . . . . . . . . . . . . . . . . . . . . . . . . . . . . . . . 4

4.4. UV-induced defects .. . . . . . . . . . . . . . . . . . . . . . . . . . . . . . . . . . . . . . . . . . . . . 4

4.5. Charge-sensitive detection in heterogeneous alloys . . . . . . . . . . . . . . . . . . . . . . . . . . . . . . . . 5

4.6. Bias-induced charging shifts in dielectric materials . . . . . . . . . . . . . . . . . . . . . . . . . . . . . . . . . . . . . . . 5

4.7. Bias-induced shifts across an operating p-n junction . . . . . . . . . . . . . . . . . . . . . . . . . . . . . . . . . . . 5

4.8. Application of square-wave (SQW) electrical pulses . . . . . . . . . . . . . . . . . . . . . . . . . . . . . . . . 6

4.9. Application of triangular-wave (TW) electrical pulses . . . . . . . . . . . . . . . . . . . . . . . . . . . . . . . . . . 9

5. Summary and conclusion . . . . . . . . . . . . . . . . . . . . . . . . . . . . . . . . . . . . . . . . . . . . 10

List of acronyms . . . . . . . . . . . . . . . . . . . . . . . . . . . . . . . . . . . . . . . 11

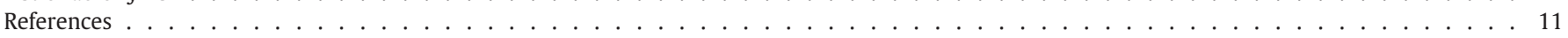

\section{Introduction}

Unlike what is generally taught in college freshman textbooks, most materials carry uncompensated electrical charges, as a result of electrification or electret formation. This phenomenon has been well-known to man for more than 2500 years, and has also been intelligently utilized for that long [1]. An "electret" is defined as a material that develops a permanent electrostatic potential or a permanent dipole moment [1-8].

Electrons are spatially localized within atoms and molecules, occupying atomic and molecular orbitals, and when larger particles or assemblies

\footnotetext{
* Corresponding author.

E-mail address: suzer@fen.bilkent.edu.tr (S. Suzer).
}

are considered, interatomic and intermolecular delocalization of electrons becomes important. Semiconducting bulk materials are best described by filled valence and empty conduction bands with an energy separation or band gap $E_{\mathrm{g}}$. However, additional electronic states due to doping or defects, imperfections at their surfaces and/or grain boundaries, as well within the lattice, commonly described as traps, impurity states, etc., contribute significantly to their electrical properties. At the other extreme are insulating materials like polymers [poly(methyl-methacrylate) (PMMA), poly(tetrafluoroethylene) (PTFE), poly(vinylidinefluoride) (PVDF)], salts $\left[\mathrm{NaCl}, \mathrm{BaF}_{2}\right]$, metal oxides such as $\mathrm{MgO}, \mathrm{Al}_{2} \mathrm{O}_{3}$ and $\mathrm{SiO}_{2}$, nitrides, and sulfides $\mathrm{ZnS}$, CdS, etc., which are described with the same language, but with larger $E_{\mathrm{g}}$ values, where electrons are localized, leading to extremely low conductivities. Especially in these latter materials, other electronic states, 
such as interface and impurity states, defect sites, etc. dominate their electrical properties [9-13]. Moreover, electrical properties of these materials are strongly influenced by external stresses, including exposure to light, energetic particles, friction, mechanical distortions, slicing, ball milling, etc., which are attributed to insertion of additional electrons and/or ions at interfaces, grain boundaries, cracks, or in bulk sites such as cavities, which can even lead to oxidation-reduction reactions [14].

In complete contrast to metallic and semiconducting systems, the atomic/molecular-level nature of electrets is poorly understood. Therefore, better understanding at the atomic and molecular level, i.e. the chemistry, is necessary for more intelligent utilization of these materials; for creating artificial muscles, and adaptive optical devices, such as lenses and diffraction gratings; mechanical actuators for control of tactile patterns of Braille interfaces; electrically refreshable displays; better control of photogeneration of charge in electro-photography, and xerography; design and fabrication of supercapacitors etc. [15-20].

Kelvin probe atomic force microscopy (KP-AFM) has been the most advanced analytical tool for probing, quantifying, and mapping the charge developed at submicron dimensions [21]. However, as in most electrical-based measurements it lacks chemical specificity. Spectroscopic techniques like infra red (IR), nuclear magnetic resonance (NMR), or variants coupled with scanning probe techniques such as near field scanning optical microscopy (NSOM) [22], have excellent chemical specificity, but they are not sensitive to charge and/or electrostatic potentials developed. One recent study reports on Raman spectroscopy having a weak sensitivity to local potential variations [23]. In this respect, electron spin resonance (ESR) and electron paramagnetic resonance (EPR) techniques have been quite successful for analyses of trapped charges on polymer and/or oxide surfaces, especially in combination with other surface-specific techniques $[9,24,25]$. However, use of these techniques is also limited since they can only probe radicals and paramagnetic species.

\section{Method}

Unlike common optical spectroscopic techniques, X-ray photoelectron spectroscopy (XPS) is a charged-particle-based chemical analysis technique, extremely sensitive to the electrical potentials developed due to uncompensated charges. In the early days of XPS, charging was considered as a nuisance for characterization of insulating (electret) materials. Hence, elaborate compensation methods were developed using low-energy electrons and/or ions [26]. However, complete removal is only an ideal, and one can learn a lot by controlled use of the charging/discharging phenomena. That is, charging can be an advantage.

The energy of the generated photoelectrons is influenced by the local electrical potential(s) $\left(V_{\mathrm{loc}}\right)$ resulting from charge accumulation, in addition to the chemical identity of the atoms, which is the mainstay of the technique, as schematically illustrated in Fig. 1; where $h \nu$, is the energy of the X-rays (1486.6 eV in our case), K.E. is the kinetic, B.E. is the binding energy of the ejected photoelectron, $\Phi$ represents the work function of the spectrometer.

There are a myriad of chemical, physical, thermal, optical, mechanical phenomena contributing to charge accumulation on materials and/ or surface structures, all amenable to charge sensitive XPS analysis. It is equally surprising that, although XPS has been utilized for more than five decades, this capability is almost completely untapped, and underutilized, except by a few groups around the globe [27-50]. In what follows, we describe the power of charge-sensitive XPS and provide a variety of applications from our recent work [37-50].

Basically, we will tap information related with the following materials' properties of a variety of samples:

i- Charging/discharging: During XPS analyses, electrons are emitted from the sample leaving a positive charge behind. Although, the initial photoemission process is very fast (femto to picoseconds), the following processes, involving filling of the resulting holes, consist of a cascade of several steps. As a result, final localization of the hole, especially in insulating materials, is slow and may require anywhere between milliseconds to several minutes. Similarly, discharging is also a relatively slow process.

ii- Photoconductivity: Creation of electron-hole pairs upon light illumination, leading to decrease in the bulk resistance of materials, also involves a cascade of processes including ionic movements and/or dipole orientation. This process is also slow and may involve milliseconds to seconds.

iii- Photovoltage or surface photo-voltage (SPV): Creation of electronhole pairs upon light illumination which is related mainly with electron movement is very fast, and requires nanoseconds or less.

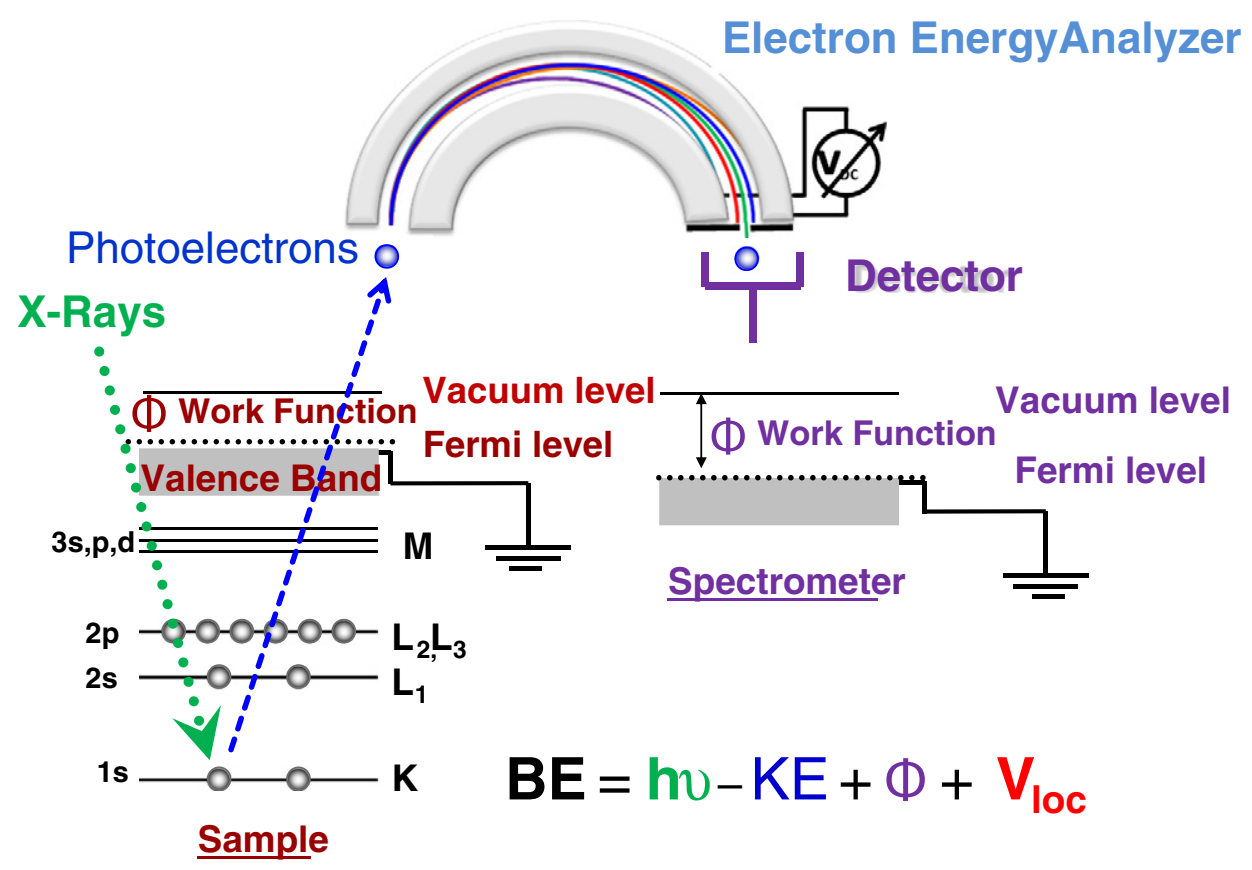

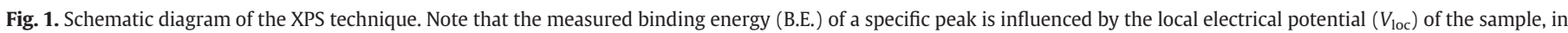
addition to its elemental nature and chemical state (chemical shift). 


\section{Materials and equipment used}

Commercially available $\mathrm{n}$ - and p-doped $\mathrm{Si}(001)$ wafers, with typical conductivities of $10-20$ and $28-31 \Omega-\mathrm{cm}$, respectively, are cleaned with $\mathrm{HF}$ before analysis. The wafers are also analyzed after growing ca. 4-12 nm-thick oxide layers by annealing in air at $700{ }^{\circ} \mathrm{C}$ for various durations. In addition, thin films of CdS, sputter deposited on $\mathrm{Si}(001)$ wafers, with nominal thickness of 10-40 $\mu \mathrm{m}$, an InGaN film, prepared by chemical vapor deposition (CVD) on sapphire; and a commercial Si diode (1N 4007), are analyzed.

A Thermo Fisher K-Alpha electron spectrometer with monochromatic AlK $\alpha$ X-rays is used for XPS analysis with an overall resolution of better than $0.3 \mathrm{eV}$. The intensity of X-ray photons focused on the surface is of the order of $10^{12}$ photons $/ \mathrm{cm}^{2}$.s. The photovoltage measurements are performed using four different continuous wave $(\mathrm{CW})$ lasers with wavelengths of $980,635,532$, and $405 \mathrm{~nm}$ and rated powers of $>25 \mathrm{~mW}$. The laser spot sizes at the sample vary between 2 and $4 \mathrm{~mm}$ in diameter. A shutter connected to a signal generator is used to turn the lasers on and off periodically.

\section{Applications}

\subsection{Application of external bias voltage}

A trivial and controlled way of incorporating charges on a conducting sample is by connecting it to an external voltage source (i.e., a battery or a power supply). This introduces additional negative charges (electrons) upon negative biasing, and positive charges (holes) upon positive bias. As shown in Fig. 2 for a $\mathrm{Si}(001)$ wafer, such a procedure simply increases the measured kinetic energy (hence, decreases the electron binding energy) of the Si2p peak by $\pm 5.00 \mathrm{eV}$ upon imposing a $5 \mathrm{~V}$ d.c. bias, without introducing additional broadening, or other spectral artifacts, such as distortion or skewing. For measuring such shifts, our precision is better than $0.05 \mathrm{eV}$. While this type of measurement provides no new information for conducting samples, it can provide a wealth of analytical information for nonconducting samples, domains, or surface structures as is demonstrated in Section 4.6 below.

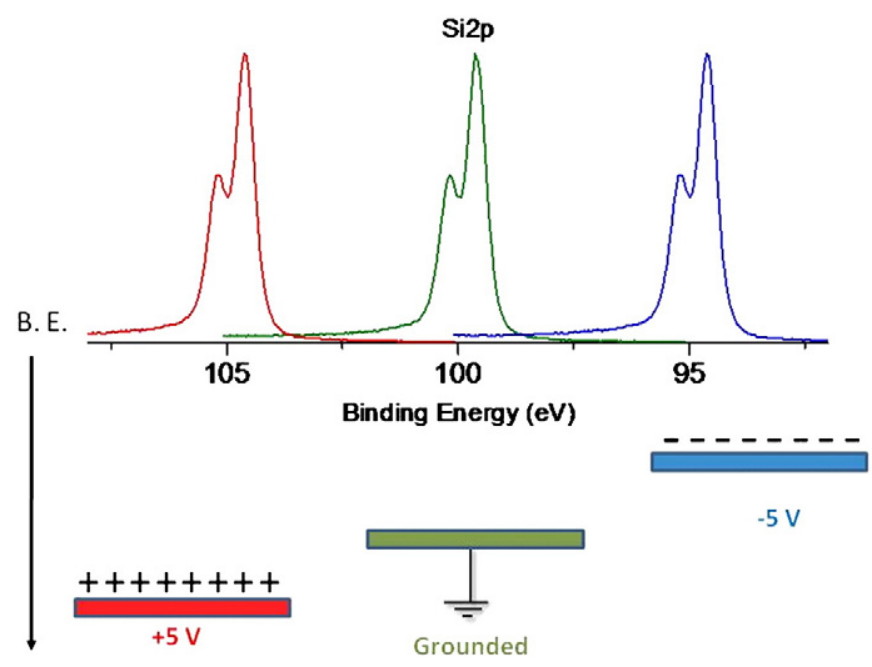

Fig. 2. XPS spectrum of the $\mathrm{Si} 2 \mathrm{p}$ region of a $\mathrm{Si}(001)$ sample recorded with the wafer grounded, after applying +5 and $-5 \mathrm{~V}$ external voltage bias. Under negative bias, the sample surface is negatively charged, and as a result the kinetic energy is increased (binding energy is decreased) by $5.00 \mathrm{eV}$. The opposite applies for positive biasing.

\subsection{Charges on semiconductors and band-bending}

Doping, or creating controlled impurities, is the most crucial step in fabrication of modern semiconducting electronic devices, and is also one of the processes leading to charge accumulation which can be measured and quantified using XPS. The conventional description of this process is by use of band-diagrams, indicating creation of electron and hole states within the bandgap of semiconductors. We will use a slightly different, more chemical description and emphasize electron transfer.

When a Si atom is replaced by an n-type dopant such as N or P, the extra electrons introduced are delocalized, and can easily be ionized/ transferred. The opposite happens for the p-type dopant. As soon as nand p-type doped samples are brought into contact with each other, connected to a common metal, or to the spectrometer, electrons from the n-side will be transferred to the p-side, causing the valence band maximum, conduction band minimum, as well as their electronic levels ( such as Si2p) to assume different energy positions, as shown in Fig. 3. These changes/shifts can be estimated using the Nernst equation, which refers to the chemical potential difference when charges are transferred [52].

Nernst Equation : $\Delta E=(R T / \nu F) * \log \left(n_{\text {fin }} / n_{\text {in }}\right)$

$$
=(0.0592 / \nu) * \log \left(n_{\mathrm{f}} / n_{\mathrm{i}}\right)
$$

In the above equation, $R(8.314 \mathrm{~J} / \mathrm{K} \mathrm{mol})$ is the gas constant, $T$ is the temperature (in Kelvin), $F$ is the Faraday constant $(96,485 \mathrm{C} / \mathrm{mol}), \nu$ is the nature of the charge transferred $(-1$ for electrons, and +1 for holes), and $n_{\text {fin }}$ and $n_{\text {in }}$ refer to the final and initial charge densities before and after transfer. The constants yield a value of $0.0592 \mathrm{~V}$ at room temperature. The intrinsic carrier density at room temperature is $1.45 \times 10^{10} \mathrm{~cm}^{-3}\left(n_{\mathrm{i}}\right)$, and the doping concentrations are $2.8 \times 10^{14}$ $\left(n_{\mathrm{e}}\right)$ and $4.7 \times 10^{14} \mathrm{~cm}^{-3}\left(n_{\mathrm{h}}\right)$ for the $\mathrm{n}$ - and the $\mathrm{p}$-Si samples we have used $[45,51]$. Hence, assuming that all of the additional electrons are transferred to or from the common metal or the spectrometer, the changes in the chemical potentials are:

$$
\begin{aligned}
\Delta E_{\mathrm{n}} & =-0.0592 * \log \left(n_{\mathrm{e}} / n_{\mathrm{i}}\right)=-0.0592 * \log \left(2.8 \times 10^{14} / 1.45 \times 10^{10}\right) \\
& =-0.25 \mathrm{eV} \\
\Delta E_{\mathrm{p}} & =+0.0592 * \log \left(n_{\mathrm{h}} / n_{\mathrm{i}}\right)=+0.0592 * \log \left(4.7 \times 10^{14} / 1.45 \times 10^{10}\right) \\
& =+0.27 \mathrm{eV} .
\end{aligned}
$$

The idea behind this description is chemical and assumes that n-Si has lost all of its electrons, and p-Si its holes. As a result, a difference in the Si2p binding energies of $0.52 \mathrm{eV}$ is predicted. However, we must emphasize that binding energies measured by XPS must be carefully referenced, since many instrumental and experimental factors influence them. The method which is the least susceptible to these factors, is performing measurements on both samples at the same time, so that most of the instrumental factors cancel. To perform such simultaneous measurement, we recorded the Si2p peaks of n-

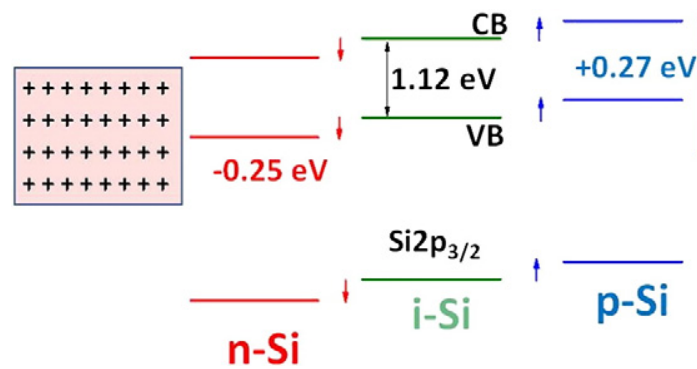

Fig. 3. A schematic diagram of the shifts in the positions of the valence band (VB), the conduction band $(\mathrm{CB})$, and the Si2p peak position with respect to doping. i-Si refers to undoped intrinsic silicon. 
and p-doped Si (001) samples, placed together in a p-n junction configuration. As shown in Fig. 4, the binding energy difference between the $\mathrm{n}$ - and p-regions is $0.18 \mathrm{eV}$, when measured without illumination. This difference is increased by illumination to $0.49 \mathrm{eV}$.

This observation is another manifestation of the surface depth sensitivity of XPS, which is typically $10-15 \mathrm{~nm}$, and stems from bandbending at the surface/vacuum interface. The potentials we calculated are for the bulk, and are modified towards the surfaces in a Coulombic (1/r) fashion [54-58]. In chemist's language, some of the lost electrons are back-transferred to the n-side such that a space-charge region of approximately $100 \mathrm{~nm}$ is developed. This is schematically described in Fig. 5 and also in Fig. 4(c). Without light, the band-bending screens the B.E. difference, but with illumination, a photovoltage is created due to generation of additional electron-hole pairs; hence a nearly flat-band condition is achieved. Note that although less than 1 of $10^{8}$ silicon atoms are replaced by the dopant (minority) atoms, the potentials developed and sensed by the majority atoms (i.e., Si) are easily measured.

Band-bending is not specific to the junction region and is present on all surfaces as depicted in Fig. 6, where variations in the position of the Si2p level are shown as the laser is sequentially turned on and off every $200 \mathrm{~s}$, and the XPS Si2p peak position is recorded at numerous $400 \mu \mathrm{m}$ spots along the line-scan across the entire $\mathrm{p}$ - and n-regions including the junction. Within the entire p-region, the binding energy of the $\mathrm{Si} 2 \mathrm{p}$ is shifted to a lower value with illumination, and to a higher one over the entire n-region.

\section{3. $\mathrm{Si} / \mathrm{SiO}_{2}$ interfacial charges}

Each interface introduces additional charges; the nature, as well as the density, of such charges is important for device performance. As an extension of our investigations, we have also recorded binding energy variations of the same $\mathrm{n}$ - and $\mathrm{p}$-Si samples after growing thermal oxide layers $\sim 8 \mathrm{~nm}$ thick, on top. For these samples, as shown in Fig. $7(\mathrm{a}-\mathrm{f})$, in addition to the $\mathrm{Si} 2 \mathrm{p}$ peak from the substrate $\left(\mathrm{Si}^{0}\right)$, we can also follow the corresponding 01s and the Si2p peak shifts from the oxide layers $\left(\mathrm{Si}^{4+}\right)$. In Fig. $7(\mathrm{~g})$, we show the variations in the oxide $\mathrm{Si} 2 \mathrm{p}$ peak position $\left(\mathrm{Si}^{4+}\right)$ for a composite sample prepared and measured using the same protocol as the substrate-only case (see

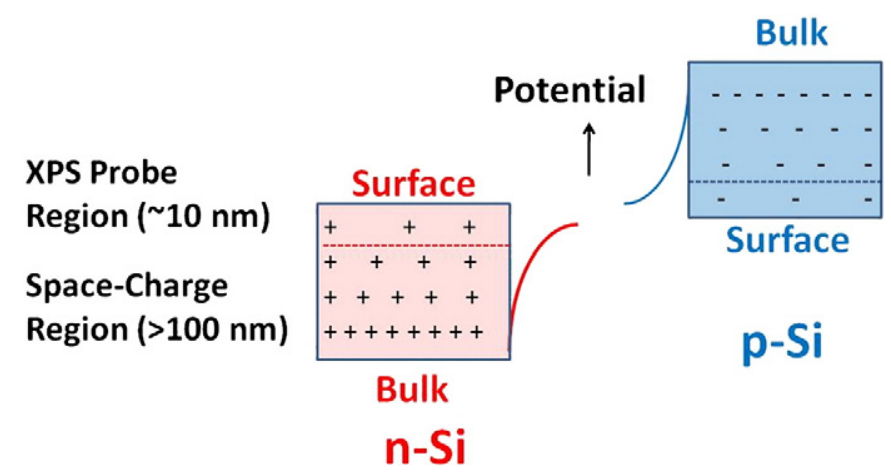

Fig. 5. Band-bending in n- and p-Si.

Section 4a). Very similar features are also observed for the Si2p peak from the substrate $\left(\mathrm{Si}^{0}\right)$. The surprising result is that there are no significant variations in the peak positions for the n-type sample, but large variations for the p-type sample [45].

The fact that both the oxide and substrate peaks are exhibiting the same shifts signifies that the shifts are strongly correlated with the interface, such that the n-Si band-bending is nearly canceled by the positive oxide charges accumulated at the interface. However, the two effects are additive for the $\mathrm{p}-\mathrm{Si}$ interface as schematically represented in Fig. 8. Although, the exact mechanism is still unclear, further experiments carried out with n- and p-Si/polystyrene, and n- and p-Si/hexane films also support these observations [53].

\subsection{UV-induced defects}

Exposure of insulating materials to energetic particles like $\gamma$-rays, $\mathrm{X}$-rays, and UV photons creates long-lasting defects such as colorcenters, resulting in modification of the electrical properties of these materials, which can also be probed by XPS. As shown in Fig. 9, longlasting charging effects on $\mathrm{SiO}_{2}$ surfaces induced by $254 \mathrm{~nm}$ UV radiation (6 Watts, low pressure Hg lamp) causes shifts in the XPS peak positions. Upon UV-irradiation through a mask, the 01s appears at two different positions. In regions exposed to UV-radiation, it appears at more negative (or less positive) potentials compared to the
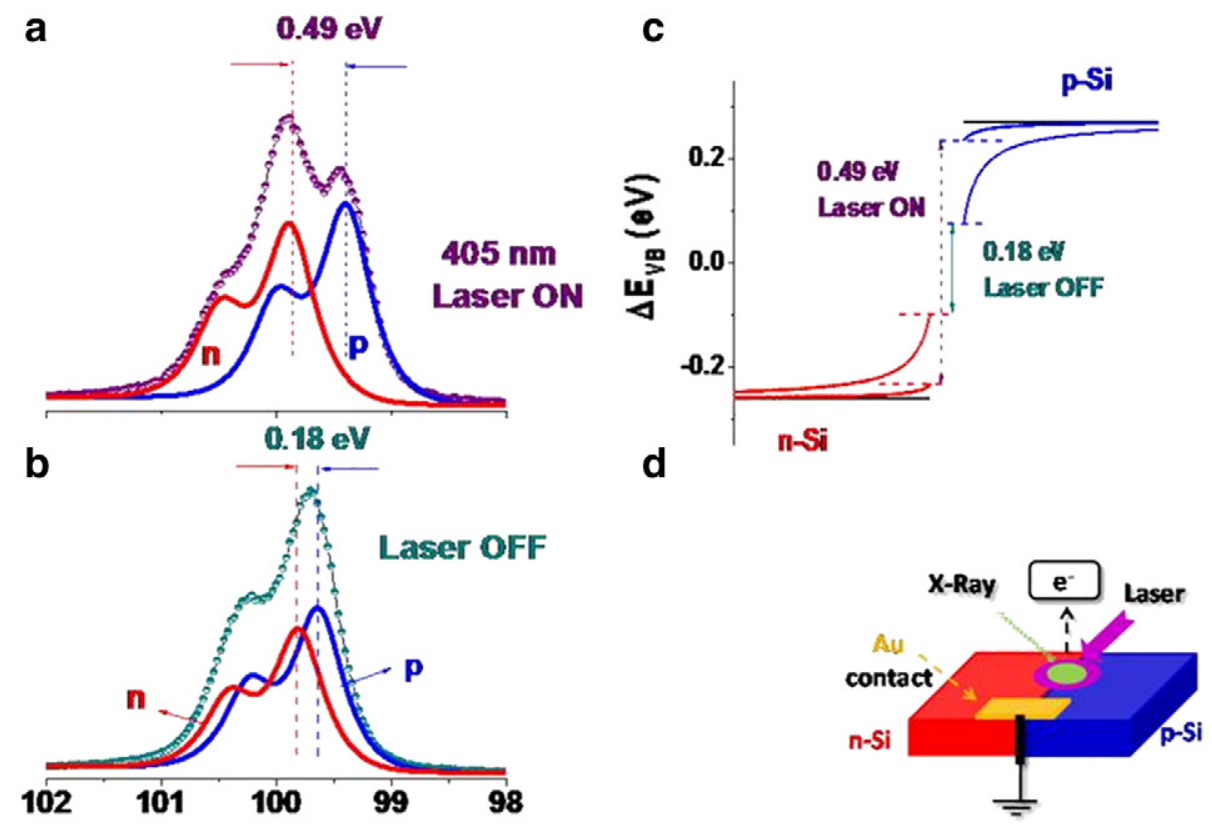

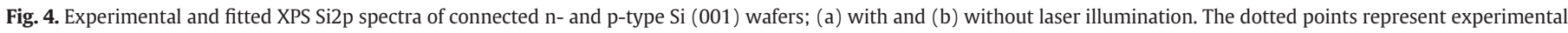

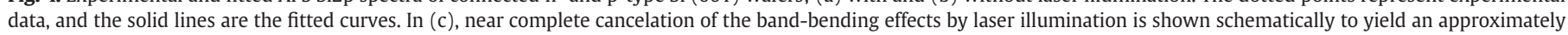
flat-band condition, and (d) shows the experimental arrangement. 


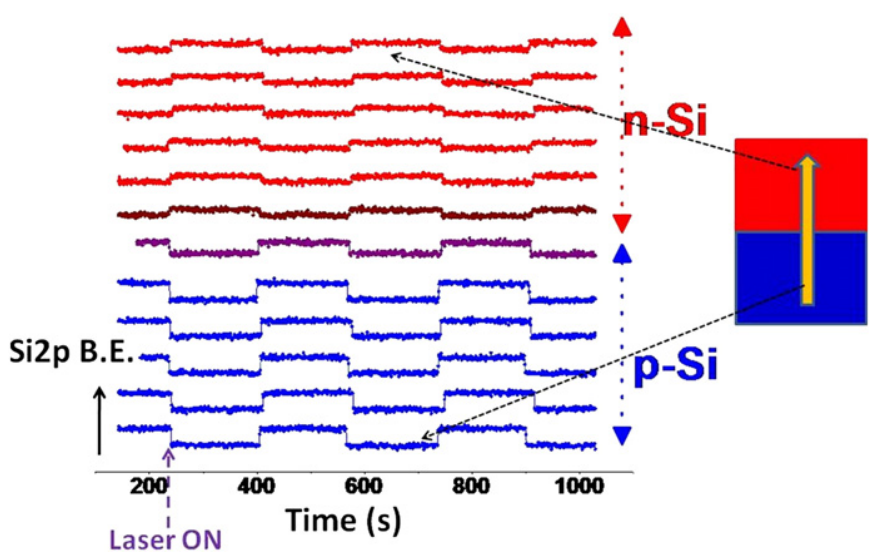

Fig. 6. Variations in the binding energy (B.E.) of the Si2p peak, recorded while the $405 \mathrm{~nm}$ laser is turned on and off every $200 \mathrm{~s}$. A $400 \mu \mathrm{m}$ X-ray spot size was used for sampling, and the line segments correspond to measurements obtained at different points, with $400 \mu \mathrm{m}$ steps, along the designated path.

unirradiated regions, and this charge contrast is stable for more than three days.

\subsection{Charge-sensitive detection in heterogeneous alloys}

A further interesting situation arises in analysis of heterogeneous compound semiconductors such as InGaN for which charge accumulation is found to be asymmetric on InN and GaN moieties for a sample with In/Ga $\sim 0.8$, as shown in Fig. 10. This difference is amplified further by illumination. Behaving like an intrinsically n-doped material, the influence of the accumulation of charges on illuminated Ga atoms is more pronounced $(>0.1 \mathrm{eV})$, and $405 \mathrm{~nm}$ radiation, above the bandgap of the material, is the most effective [59]. This is indeed one of the triumphs of detection of chemically specific charge accumulation.

\subsection{Bias-induced charging shifts in dielectric materials}

Application of external voltage bias to nonconducting samples introduces additional charging shifts which are strongly polarity dependent, as shown in Fig. 11 for a $\mathrm{Si}(001)$ wafer with an $~ 8 \mathrm{~nm}$ oxide layer. Upon application of a $-10 \mathrm{~V}$ d.c. bias, all peaks are shifted to $10.00 \mathrm{eV}$ higher kinetic energies (lower binding energies) as is the case for the $\operatorname{Si} 2 \mathrm{p}\left(\mathrm{Si}^{0}\right)$ peak from the conducting substrate, but only $8.90 \mathrm{eV}$ shift is observed for the oxide $\left(\mathrm{Si}^{4+}\right)$. In the bottom of the same figure, we show the same spectra after correcting for the imposed bias shifts.

The tabulated binding energy difference between the oxide $\left(\mathrm{Si}^{4+}\right)$ and the substrate $\mathrm{Si} 2 \mathrm{p}\left(\mathrm{Si}^{0}\right)$ peaks is $3.2 \mathrm{eV}[60,61]$ for the point of zero-charge (PZC) condition [62], which is an ideal and experimentally difficult to achieve. For real samples, the oxide layer is either positively charged and appears at a higher binding energy position, or negatively charged at a lower position. Note that upon negative biasing, the positive charging of the oxide increases since all of the neutralizing lowenergy electrons from the flood-gun and/or other sources are repelled. This procedure provides an important experimental asset for controlling the charging, which in turn has been utilized for a host of material characterization and analytical applications, reported by our group and others [27-50].

\subsection{Bias-induced shifts across an operating $p$ - $n$ junction}

A p-n junction, the simplest fundamental unit of modern electronic and photovoltaic devices, was examined by XPS during operation. We have used a commercially available Si-diode (1N 4007) after mechanically removing the protective polymer coating and sputter etching the device with a $(1 \mathrm{keV}, 15 \mu \mathrm{A}) \mathrm{Ar}^{+}$ion-gun for $\sim 10$ minutes. For survey scans, an X-ray beam size of $400-\mu \mathrm{m}$ diameter was used, but for the data presented below, either 100 - or 50 - $\mu$ m-diameter X-ray spot sizes were used for both static recording of spectra as well as for line scans with steps varying from 30 to $100 \mu \mathrm{m}$ between analysis points.

Si2p spectra from a p-n junction analyzed with $100 \mu \mathrm{m}$ steps under different bias conditions are displayed in Fig. 12, where the diode was grounded from the n-side and the potential was applied from the p-side. Since parts of the sample with residual polymer were charging, this mode of connection was preferred in order not to disturb the flood-gun operation. However, grounding the p-side and applying the bias from the n-side gave similar results [50]. Note that this mode of operation is very different from the previous ones, since we are not subjecting a bias potential to the entire sample and grounding is achieved through the spectrometer via the photoelectrons ejected. By applying a potential to one side of the device and grounding the other side, a significant additional current passes through the sample.

When grounded, we observe a metallic $\left(\mathrm{Si}^{0}\right)$ and an oxide $\left(\mathrm{Si}^{\mathrm{X}+}\right)$ peak, where the metallic peak is deconvoluted into 2 spin-orbit doublets with the theoretical $0.608 \mathrm{eV}$ splitting and assigned to $\mathrm{p}-\mathrm{Si}$ and
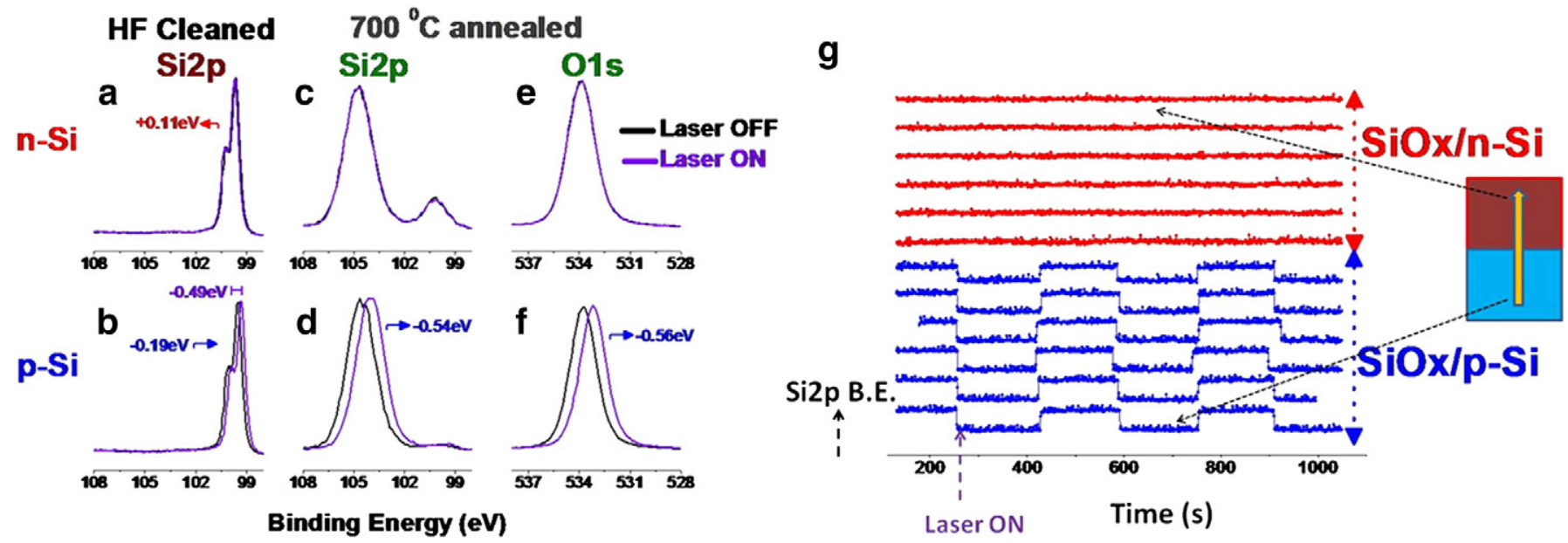

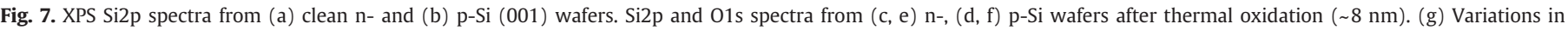

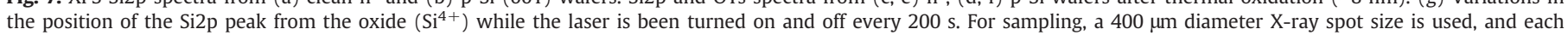
point corresponds to different positions with $400 \mu \mathrm{m}$ steps along the designated path. 

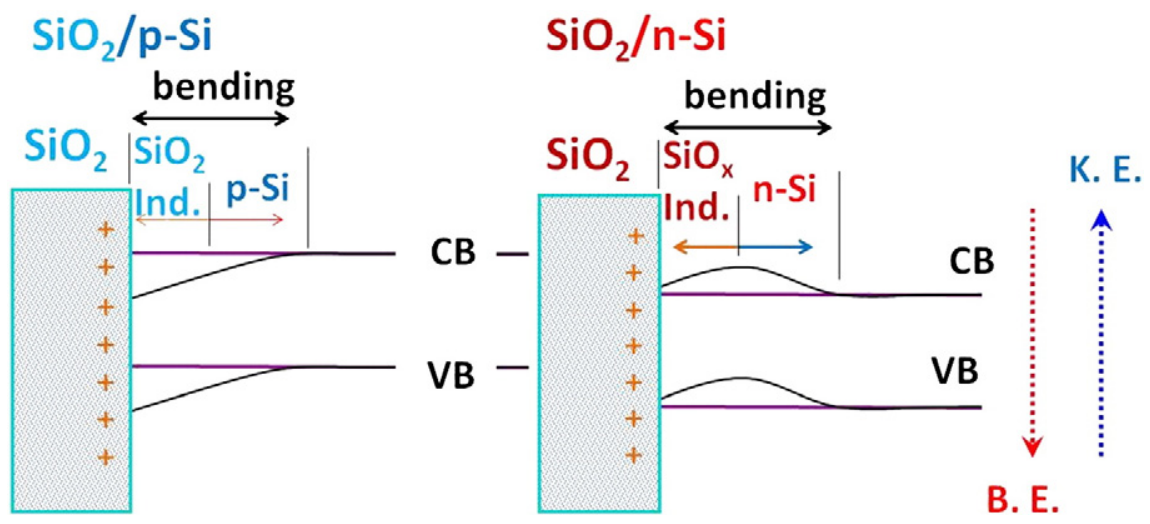

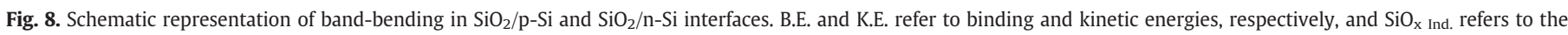
potential induced by the oxide layer.

n-Si components at approximately the same binding energy of $99.8 \mathrm{eV}$ [61]. Under forward bias $(-8 \mathrm{~V})$, the $\mathrm{Si}^{0}$ feature becomes broader, but can again be fit with an n-component, unshifted, and a p-component, shifted by $\sim-0.5 \mathrm{eV}$. Under reverse bias of $+8 \mathrm{~V}$, a dramatic splitting is observed, where, while the n-component remains unshifted, the p-component is exactly $+8.0 \mathrm{eV}$ up-shifted in the binding energy scale. The oxide peak is also split correspondingly.

A wider energy spectra recorded in $30 \mu \mathrm{m}$ steps line-scan mode across the $\mathrm{p}-\mathrm{n}$ junction under $+6 \mathrm{~V}$ reverse bias is displayed in Fig. 13. As shown, the Si2p peak as well as the Cu3s and the Pb4f peaks of the connecting wires exhibit similar shifts. All peaks are doubled traversing the junction, since the lateral resolution, $100 \mu \mathrm{m}$, is not sufficient to distinguish the $\mathrm{n}$-side from the $\mathrm{p}$-side. This procedure not only extracts dopant dependent information, but is also applicable for assessing and controlling device performance.

\subsection{Application of square-wave (SQW) electrical pulses}

Electrical pulses can also be employed to induce charging shifts using XPS spectra to probe the dynamics. Application of square-wave pulse with an amplitude of $10 \mathrm{~V}$ to a gold metal strip is shown in Fig. 14. Such a procedure splits the peaks at $\pm 10.00 \mathrm{eV}$ positions for a conducting sample yielding an exact difference of $20.00 \mathrm{eV}$ between them. With charging systems, i.e. a resistive path, the splitting is less than $20.00 \mathrm{eV}$, especially at lower frequencies, since ample time is allowed for the system to charge and discharge, thus introducing

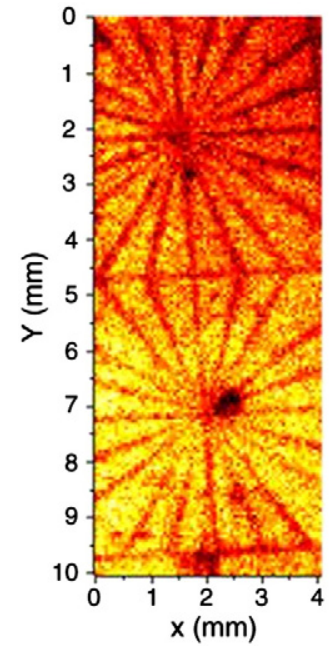

O1s at (a) $533.44 \mathrm{eV}$

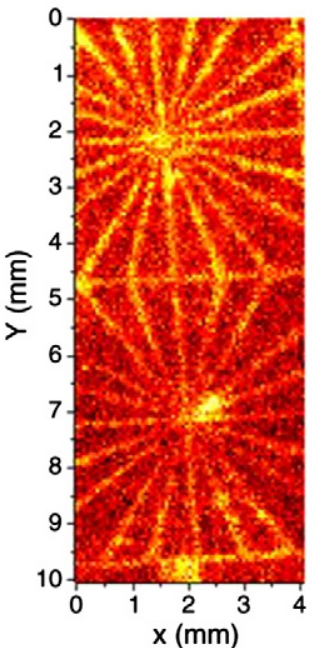

(b) $530.29 \mathrm{eV}$

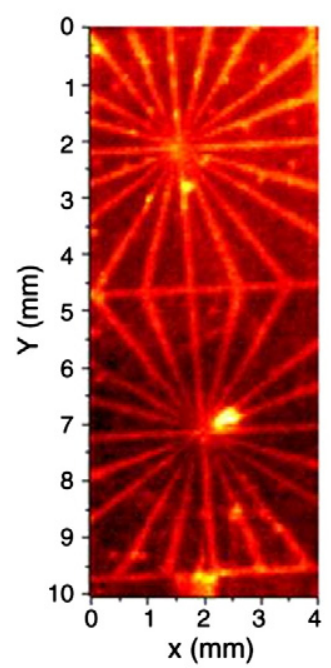

(c) 01s B.E. Shift

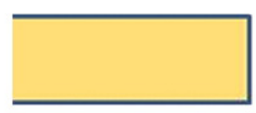

p-Si

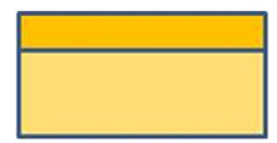

Thermal Oxide

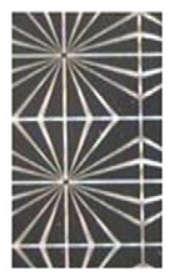

Mask

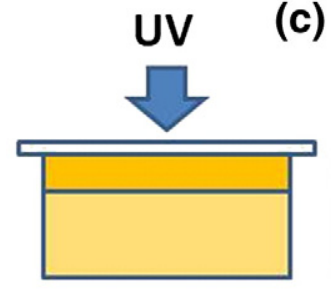

UV Exposure XPS Analysis

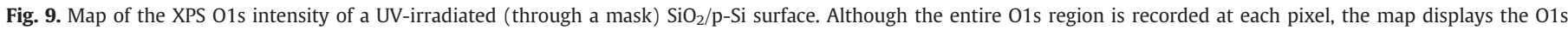

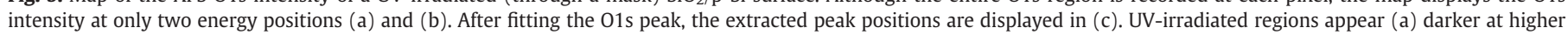
B.E. but lighter (b) at the lower one. The irradiated regions are at more negative potentials compared to the dark regions. 


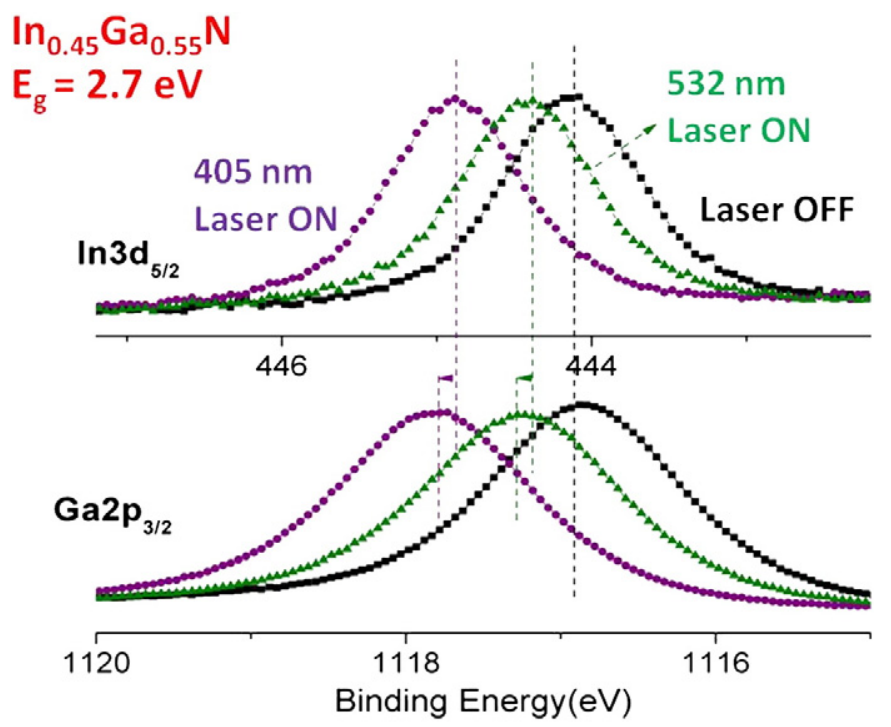

Fig. 10. The $\operatorname{In} 3 d_{5 / 2}$ and $G a 2 p_{3 / 2}$ peaks recorded while the $\operatorname{In}_{0.45} G_{0.55} \mathrm{~N}$ sample is subjected to illumination with different lasers. The photoinduced shifts in Ga peak are more pronounced compared to that in the In peak.

capacitance [39-42]. In order to simulate an electret or a dielectric film, we incorporated an external resistor (R) and a capacitor (C) in parallel, before imposing the voltage stress to the Au sample under investigation.

This type of approach can also be applied to other systems. For example, both the electrical and optical excitation dependences of on an HF cleaned p-type Si samples are probed by recording Si2p spectra, as shown in Fig. $15(\mathrm{a}-\mathrm{c})$. A $-0.19 \mathrm{eV}$ peak shift between the $405 \mathrm{~nm}$ laser off and on states is measured at three different conditions: (a) sample connected to the ground, and (b) subjected to $1 \mathrm{kHz}$ and (c) $0.001 \mathrm{~Hz}$ square-wave electric pulses. For n-type $\mathrm{Si}$, the peak shifts in the opposite direction $(+0.11 \mathrm{eV})$, as was shown in Figs. 5, 6, and

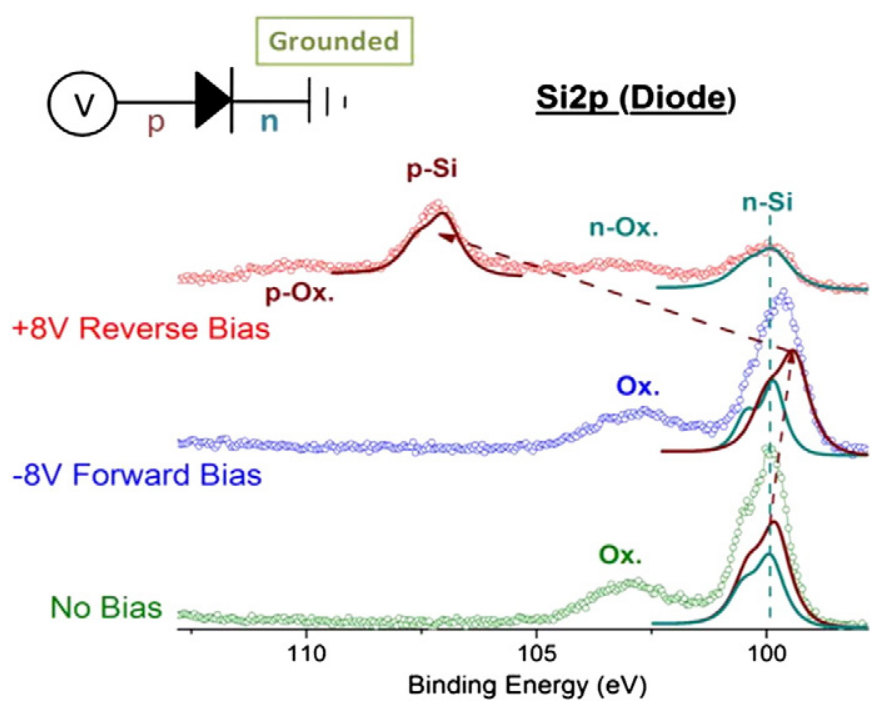

Fig. 12. XPS spectra of the Si2p region of a p-n junction Si-diode recorded; under: 0 bias, $-8 \mathrm{~V}$ forward, and $+8 \mathrm{~V}$ reverse bias. The inset schematically displays the electrical connections [50].

7. These results reveal that the surface photovoltage developed on both the $\mathrm{n}$ - and $\mathrm{p}$-Si samples does not exhibit any bias or frequency dependence [44]. The responses to photoillumination are instantaneous in the vacuum environment, as expected, and time constants for the surface photovoltage transients are much faster than our experimental capability $(<10 \mu \mathrm{s})$ [54-58].

However, when an $\sim 4$ nm-thick oxide dielectric layer is thermally grown on the Si substrate, the responses to both external electrical and optical excitation sources become more complex as shown in Fig. 16. As discussed in Section 4.3, the Si2p appears as two peaks, a broad one from the oxide layer, where silicon atoms have mostly +4 oxidation states, and a narrow one with a $0.608 \mathrm{eV}$ spin-orbit coupling,

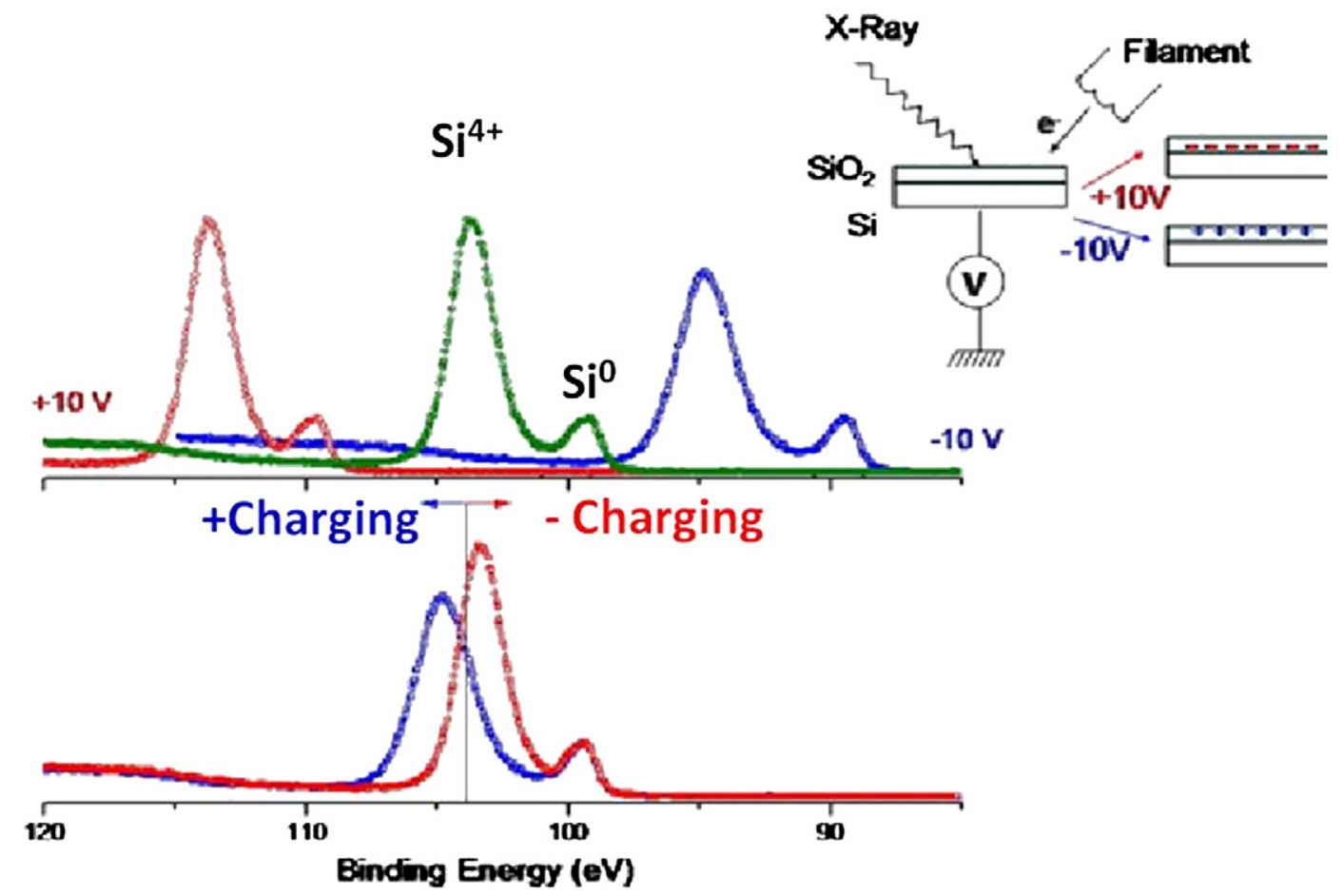

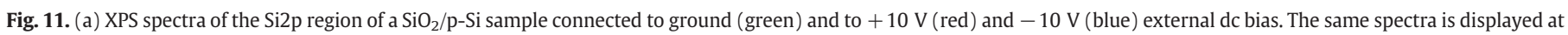
the bottom, after correcting for the $10 \mathrm{~V}$ bias. The thickness of the silica overlayer is $\sim 8 \mathrm{~nm}$, and the inset schematically shows the expereimental set-up. 


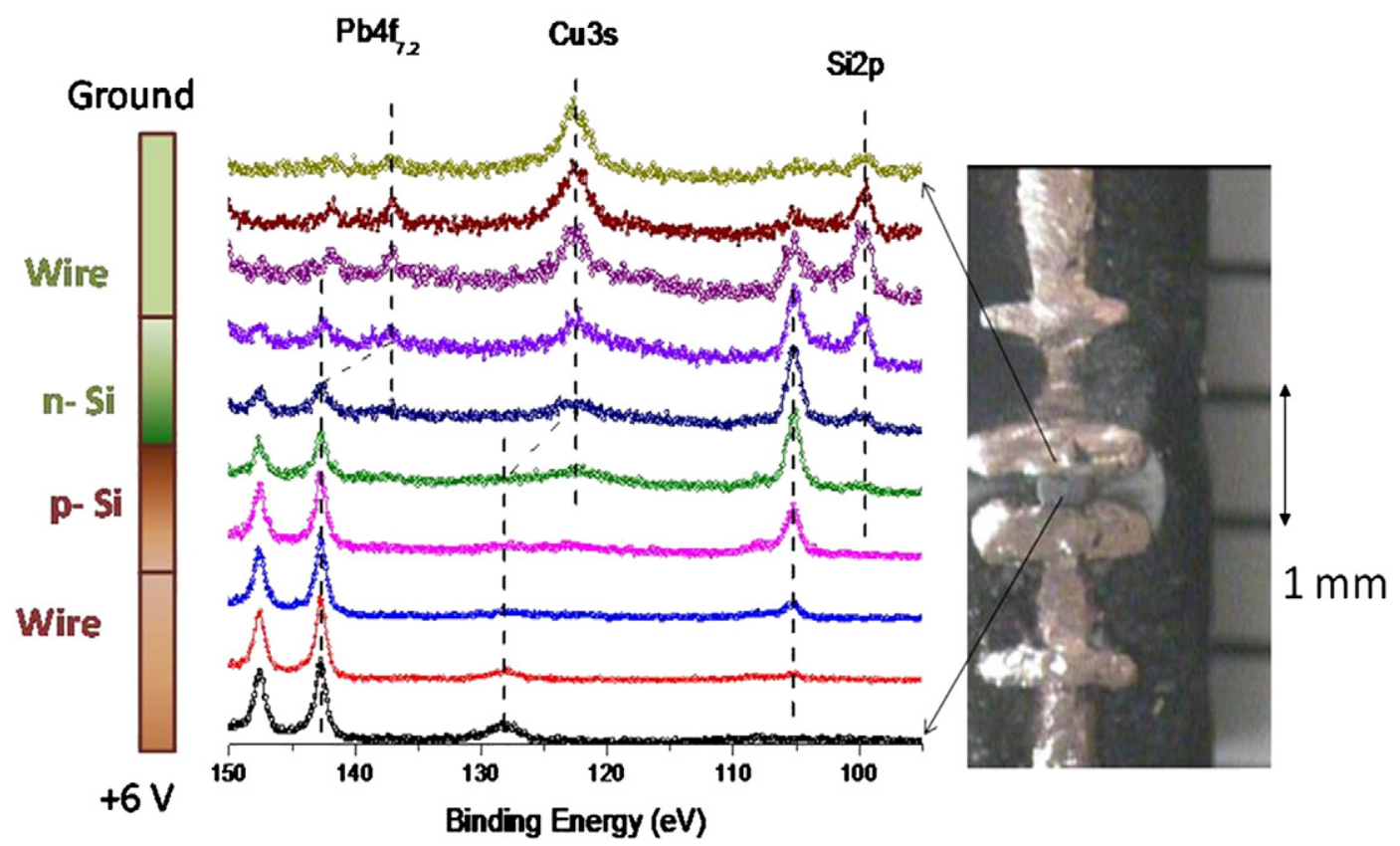

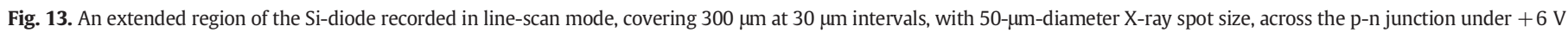
reverse bias. Spectral features of the connecting metal wires follow the same voltage variations as the Si2p peak. A photograph of the device is shown in the inset.

belonging to $\mathrm{Si}^{0}$. The binding energy difference between the two peaks varies around $3-4 \mathrm{eV}$, with respect to charging of the oxide layer $[60,61]$. Since, the square-wave excitation splits the peaks, one ends up with four peaks.

As shown in the figure, the binding energy difference between the split oxide peaks is $20.00 \mathrm{eV}$ at the higher frequency of square-wave excitation, but is smaller at the lower frequency, in contrast to $\mathrm{Si}^{0}$, which is $20.00 \mathrm{eV}$ at both frequencies. Moreover, upon illumination with the $405 \mathrm{~nm}$ laser, we also observe a frequency dependence of the binding energy difference of the split oxide peaks, but not of the $\mathrm{Si}^{0}$. The interpretation of these observations is as follows: the $\sim 4 \mathrm{~nm}$ thick oxide layer has both slow and fast components, stemming from photoconductivity (slow) and charging (slow) as well as (fast) surface photovoltage (SPV) processes, whereas the $\mathrm{Si}^{0}$ substrate displays only the fast SPV component.

In another example, XPS spectra from a CdS film, sputter deposited onto a $\mathrm{Si}(001)$ substrate, was measured at a high $(10 \mathrm{kHz})$ and a low $(0.001 \mathrm{~Hz})$ frequency, and under $405 \mathrm{~nm}$ laser illumination at different powers, obtained by incorporating a neutral density filter (NDF), as shown in Fig. 17. At the higher frequency, the Cd3d peaks split at $\pm 10 \mathrm{~V}$, display uniform shifts, with respect to the laser intensity, as the result of photoconductivity changes. Upward band-bending of the surface photovoltage is the dominant process causing the shifts. However, at the lower frequency the charging effects are asymmetrically shifted, similar to the $\sim 4$ nm-thick silicon oxide layer discussed above. As shown in Fig. 17(b), under $+10 \mathrm{~V}$, the sample is allowed to

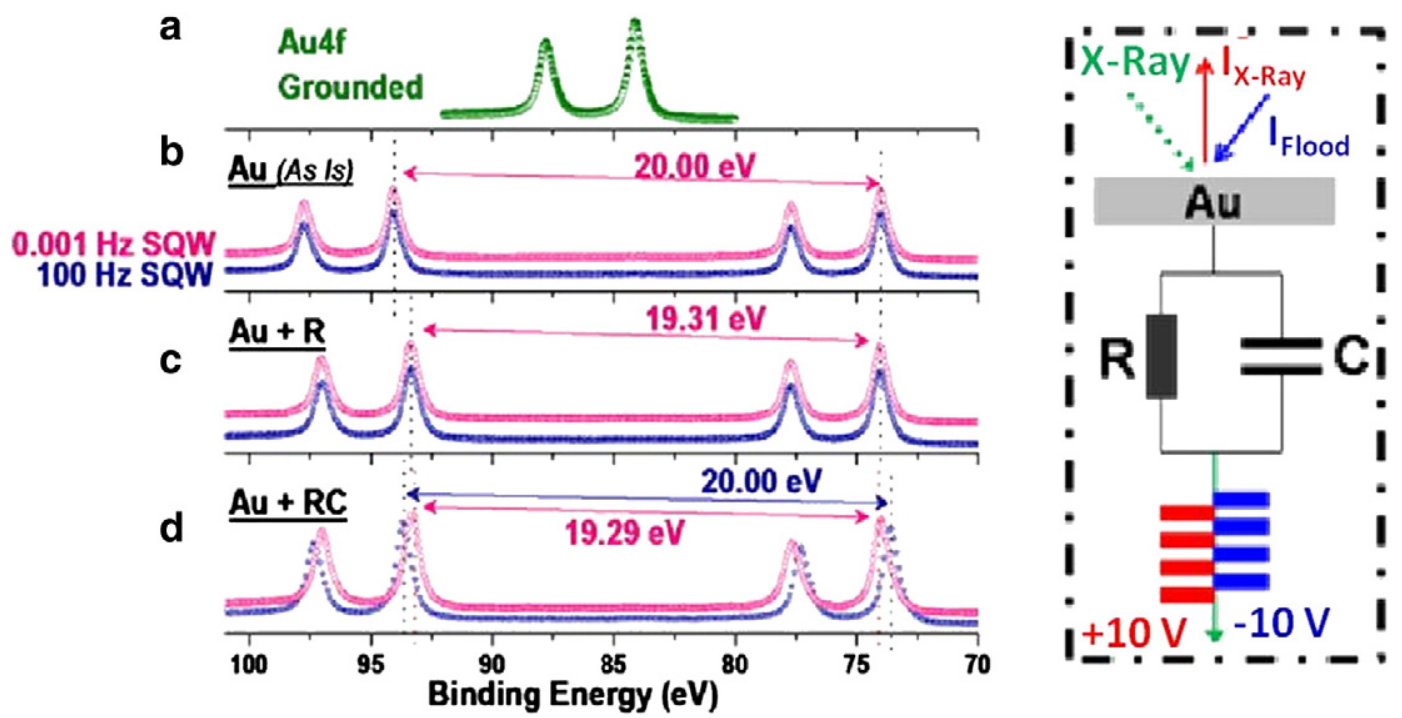

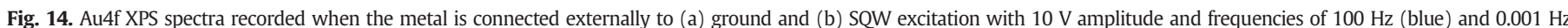

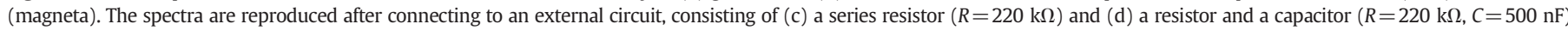

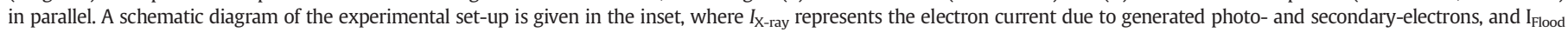
is the current due to the flood-gun used. 


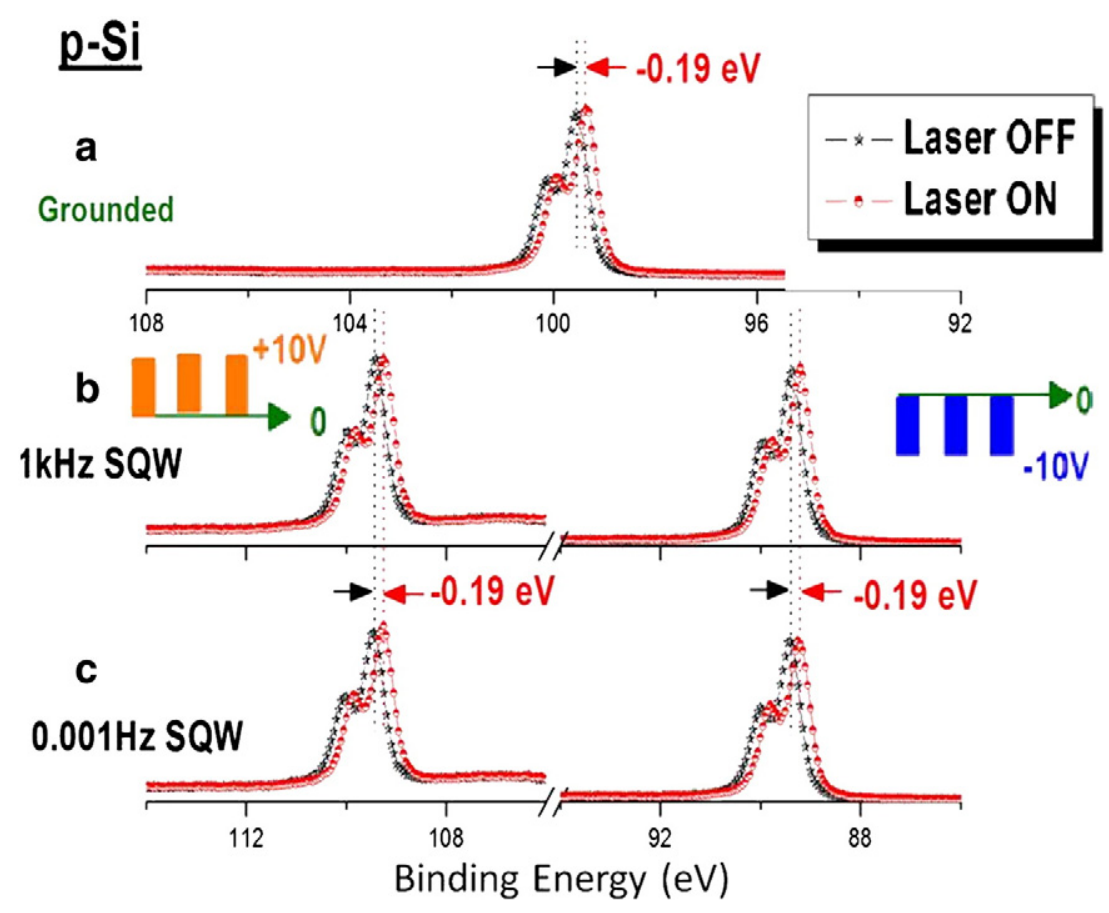

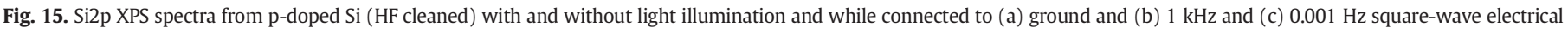
stress with an amplitude of $10 \mathrm{~V}$.

accumulate negative charges from the flood gun electrons, while with the $-10 \mathrm{~V}$ stress, the sample accumulates more positive charge. Upon photoillumination, and as the result of the decrease in the resistance, a certain amount of charge dissipation takes place in both positive (shifts to a higher binding energy position), and negative cycles (reverse). Therefore, the changes in photoconductivity, surface photovoltage, and negative charge dissipation are all in the same direction at the $+10 \mathrm{~V}$ cycle, so that they produced larger photoshifts. In contrast, during the $-10 \mathrm{~V}$ cycle, dissipation of the positive charge and surface photovoltage are in opposite directions; hence they almost cancel each other as shown in Fig. 17(b) [44]. Here again, we learn from the observed binding energy shifts that in CdS fast SPV and slow charging and photoconductivity processes are operative, and contributions of these three processes can be entangled by suitable combination of the SQW frequency and photoillumination.

For photoactive materials such as $\mathrm{CdS}$ and GaN, binding energy shifts are additionally influenced by both the wavelength and the intensity of the light source used for illumination. Through analysis of the frequency-dependent response, it is possible to determine the chemical as well as physical (ions, dipoles, electron-hole pairs, etc.) nature of the photoactive sites and/or defects.

\subsection{Application of triangular-wave (TW) electrical pulses}

A triangular wave excitation can also be utilized to record changes in peak positions as a function of the applied voltage resulting in a

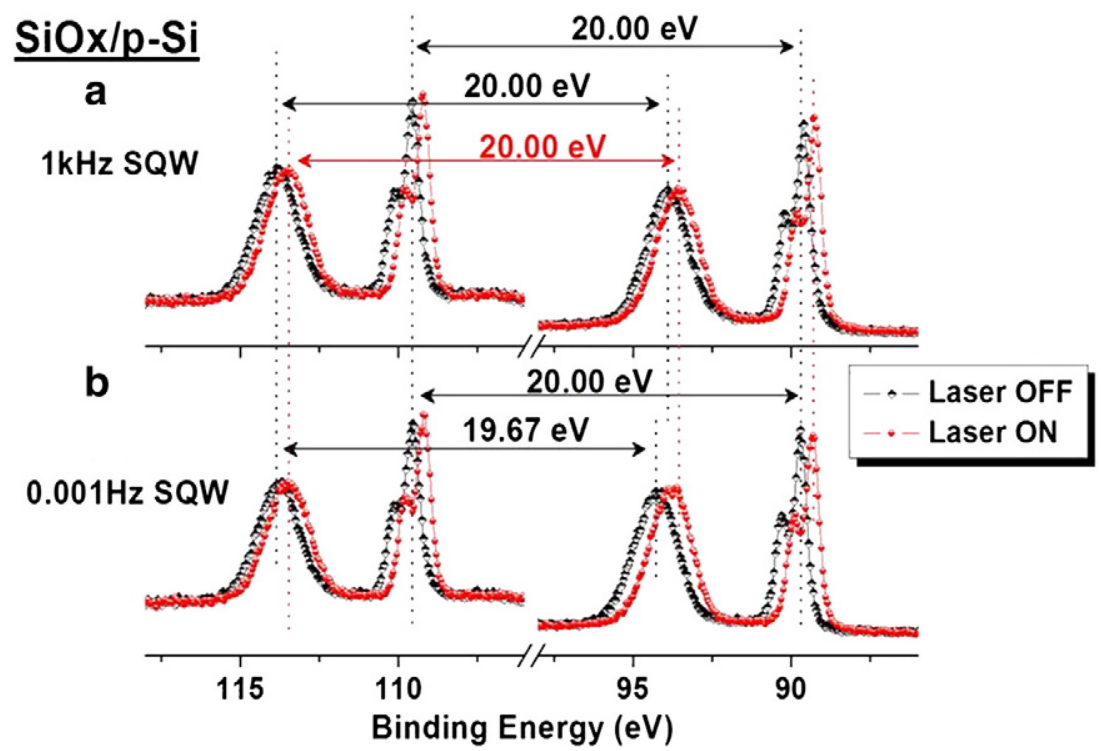

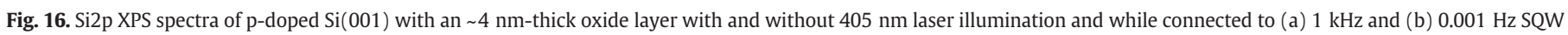
electrical pulses with amplitude of $10 \mathrm{~V}$. 
a

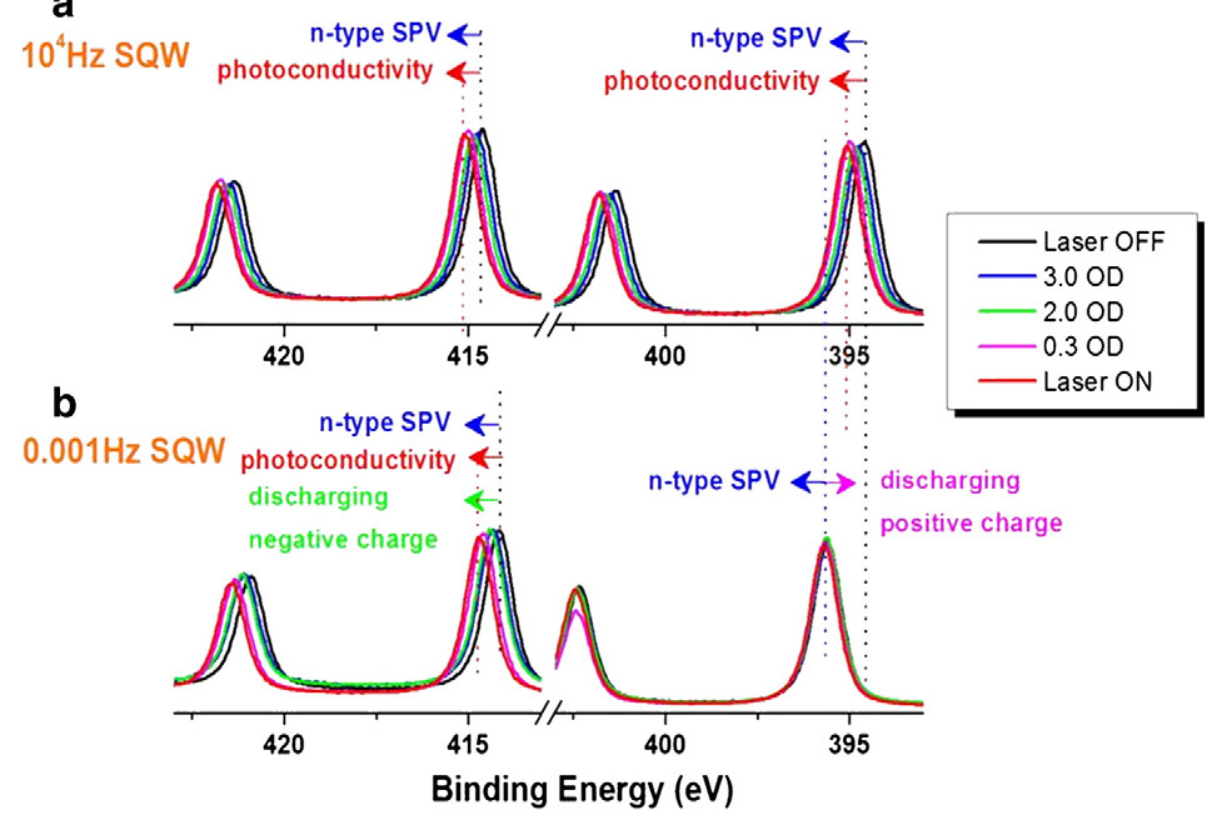

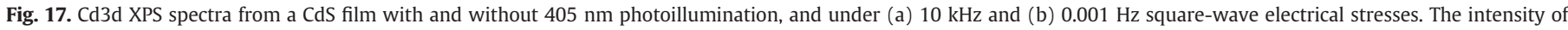
excitation source is tuned with a neutral density filter (NDF).

situation similar to recording I-V characteristics of a diode. The results are akin to what was shown in Fig. 12, where instead of recording XPS spectra at some discrete d.c. potentials, the Si2p region is now recorded in a 2 second-long snap-shot mode, with somewhat poorer resolution, while the potential is scanned linearly from -8 to $+8 \mathrm{~V}$ (Fig. 18). All spectral features are reproduced, including splitting of the peaks into two components under reverse bias, representing the p-side and the n-side of the junction, and a sharp cut-off voltage is clearly visible, corresponding to the rectifying action of the diode [50]. For the data presented in Fig. 18, the repetition rate was 1000 s, but faster scans (not shown) up to $0.1 \mathrm{~Hz}$ still reflect all of the spectral features as well as the rectifying action of the device.

\section{Summary and conclusion}

We have shown that by combining d.c. and a.c. electrical and optical stimuli to the sample, while recording XPS spectra, polarity and frequency dependence of the charging and/or photovoltage shifts can be probed covering a wide frequency range from $10^{-3}$ to $10^{6} \mathrm{~Hz}$. The approach is applicable to both thin films and bulk materials. These shifts

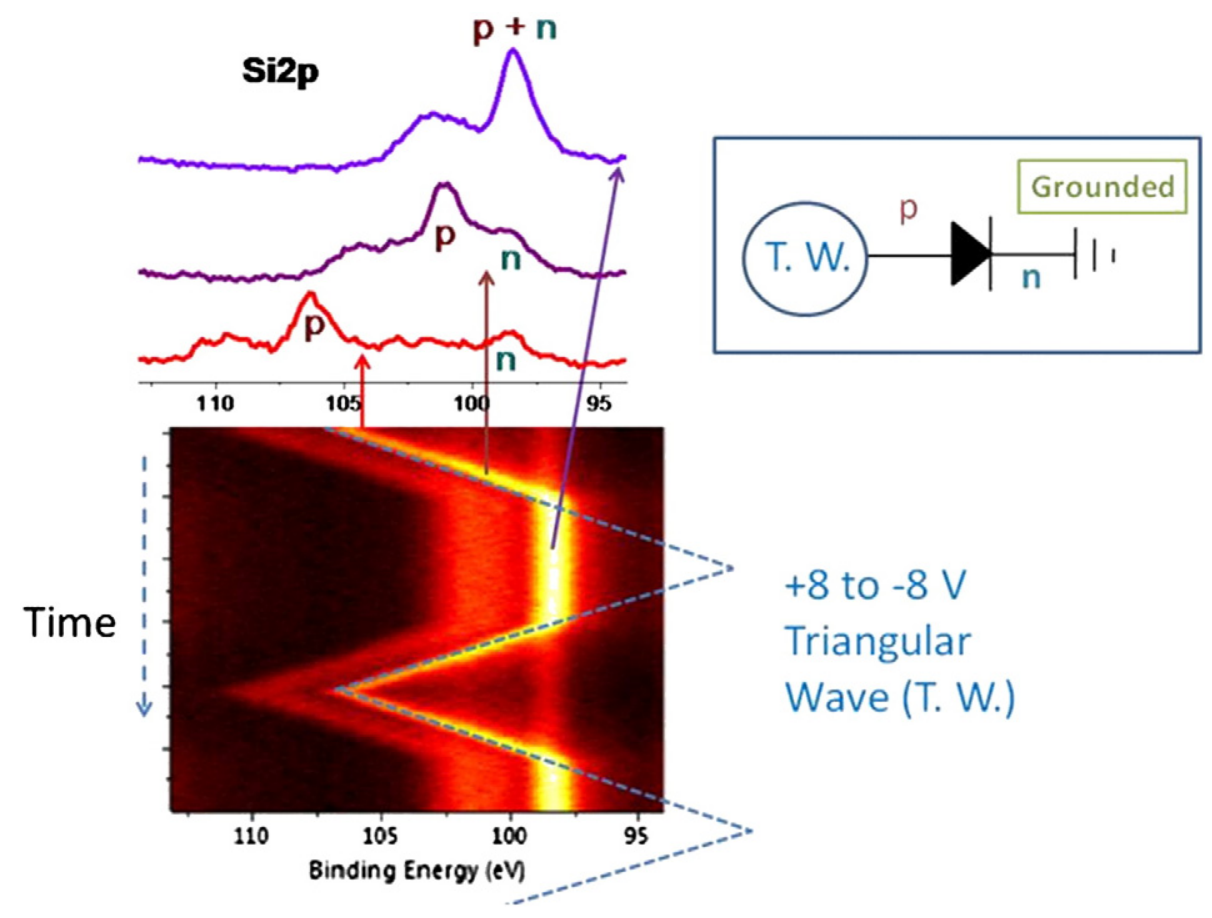

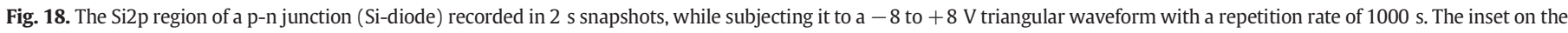

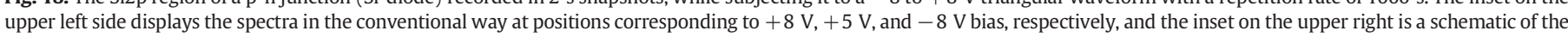
operation. 
are utilized to probe and obtain qualitative and quantitative information related to:

- Nature of the dopant, as well as band-bending in n- and p-doped Si samples.

- Interfacial charges and band-bending in $\mathrm{SiO}_{2} / \mathrm{Si}$ interfaces for $\mathrm{n}$ and $\mathrm{p}$-Si samples.

- Surface photovoltage development on In and Ga atoms in an InGaN sample.

- External bias polarity dependence and photoillumination in thin $(\sim 4 \mathrm{~nm}) \mathrm{SiO}_{2}$ layers.

- Effect of forward and reverse biasing on n- and p-domains of an operating Si p-n junction.

- Dynamics of electron and photoinduced charge accumulation and dissipation in: (i) a $\mathrm{Si}$ p-n junction, (ii) an 4-nm-thick $\mathrm{SiO}_{2}$ layer, and (iii) a CdS film.

$\begin{array}{ll}\text { List of acronyms } \\ \text { B.E. } & \text { binding energy } \\ \text { CW } & \text { continuous wave } \\ \text { EPR } & \text { electron paramagnetic resonance spectroscopy } \\ \text { ESR } & \text { electron spin resonance spectroscopy } \\ \text { IR } & \text { infra red spectroscopy } \\ \text { K.E. } & \text { kinetic energy } \\ \text { KP-AFM } & \text { Kelvin-probe atomic force microscopy } \\ \text { NMR } & \text { nuclear magnetic resonance spectroscopy } \\ \text { NSOM } & \text { near field scanning optical microscopy } \\ \text { PMMA } & \text { poly(methyl-methacrylate) } \\ \text { PTFE } & \text { poly(tetrafluoroethylene) } \\ \text { PVDF } & \text { poly(vinylideneflouride) } \\ \text { PZC } & \text { point of zero charge } \\ \text { SPV } & \text { surface photo voltage } \\ \text { SQW } & \text { square wave } \\ \text { TW } & \text { triangular wave } \\ \text { UV } & \text { ultra violet } \\ \text { XPS } & \text { X-ray photoelectron spectroscopy }\end{array}$

\section{References}

[1] In: G.M. Sessler (Ed.), Topics in Applied Physics, vol. 33, Springer, Berlin, 1987.

[2] R. Schwodiauer, G.S. Neugschwandtner, S. Bauer-Gogonean, S. Bauer, Appl. Phys. Lett. 76 (2000) 2612

[3] H. Amjadi, J. Electrostat. 48 (2000) 179; M. Paajanen, H. Valimaki, J. Lekkala, J. Electrostat. 48 (2000) 193.

[4] R. Heydt, R. Pelrine, J. Joseph, J. Eckerle, R. Kornbluh, J. Acoust. Soc. Am. 107 (2000) 833.

[5] L.S. McCarty, G.M. Whitesides, Angew. Chem. Int. Ed. 47 (2008) 2188.

[6] C.-Y. Liu, A.J. Bard, Chem. Phys. Lett. 480 (2009) 145.

[7] S.Y. Chou, L. Zhuang, J. Vac. Sci. Technol., B 17 (1999) 3197; E. Schaffer, T. Thurn-Albrecht, T.P. Russell, Nature 403 (2000) 874.

[8] M.D. Morariu, N.E. Voicu, E. Schaffer, Z. Lin, T.P. Russell, U. Steiner, Nat. Mater. 2 (2003) 48

[9] S. Pelfrey, T. Cantu, M.R. Papantonakis, D.L. Simonson, R.A. McGill, J. Macossay, Polym. Chem. 866 (2010).

[10] M. Sakaguchi, Y. Miwa, S. Hara, Y. Sugino, K. Yamamoto, S. Shimada, J. Electrostat 62 (2004) 35.

[11] M. Chiesa, M.C. Paganini, E. Glamello, D.M. Murphy, C.D. Valentin, G. Pacchionim, Acc. Chem. Res. 39 (2006) 861
[12] T. Konig, G.H. Simon, H.-P. Rust, G. Pacchioni, M. Hyde, H.-J. Freund, J. Am. Chem. Soc. 131 (2009) 17544.

[13] H.-M. Benia, P. Myrach, N. Nilius, H.-J. Freund, Surf. Sci. 604 (2010) 435.

[14] C.-Y. Liu, A.J. Bard, J. Am. Chem. Soc. 131 (2009) 6397.

[15] P. Brochu, Q. Pei, Macromol. Rapid Commun. 31 (2010) 10.

[16] M. Aschwanden, A. Stemmer, Opt. Lett. 31 (2006) 2610.

[17] S. Rosset, M. Niklaus, P. Dubois, H.R. Shea, Adv. Funct. Mater. 19 (2009) 470.

[18] In: F. Carpi, D. De Rossi, R. Kornbluh, R. Pelrine, P. Sommer-Larsen (Eds.), Dielectric Elastomers as Electromechanical Transducers, Elsevier, Amsterdam, 2008.

[19] S. Friedle, S.W. Thomas III, Angew. Chem. Int. Ed. 49 (2010) 7968.

[20] D.H. Wang, R. Kou, D. Choi, Z.G. Yang, Z.M. Nie, J. Li, L.V. Saraf, V. Laxmikant, D.H. Hu, J.G. Zhang, G.L. Graff, J. Liu, M.A. Pope, I.A. Aksay, ACS Nano 4 (2010) 1587.

[21] H.O. Jacobs, P. Leuchtmann, O.J. Homan, A. Stemmer, J. Appl. Phys. 84 (1998) 1168.

[22] H.P. Yoon, M.M. Maitani, O.M. Cabarcos, L.T. Cai, T.S. Mayer, D.L. Allara, Nano Lett. 10 (2010) 2897

[23] H.T. Baytekin, A.Z. Patashinski, M. Branicki, B. Baytekin, S. Soh, B.A. Grzybowski, Science 333 (2011) 308

[24] M. Sterrer, E. Fiscbah, T. Risse, H.-J. Freund, Phys. Rev. Lett. 94 (2005) 186101.

[25] H.-J. Freund, N. Nillius, T. Risse, S. Schauermann, T. Schmidt, ChemPhysChem 12 (2011) 79.

[26] J. Cazaux, J. Electron. Spectrosc. Relat. Phenom. 105 (1999) 155.

[27] K. Shabtai, I. Rubinstein, S.R. Cohen, H. Cohen, J. Am. Chem. Soc. 122 (2000) 4959.

[28] M. Dubey, L. Gouzman, S.L. Bernasek, J. Schwartz, Langmuir 21 (2006) 4649.

[29] H. Cohen, R. Maoz, J. Sagiv, Nano Lett. 6 (2006) 2462.

[30] G. Nesher, A. Vilan, H. Cohen, D. Cahen, F. Amy, C. Chan, J. Hwang, A. Kahn, J. Phys. Chem. B 110 (2006) 14363.

[31] H. Cohen, O.V. Zenkina, A.D. Shukla, M.E. van der Boom, J. Phys. Chem. B 110 (2006) 1506.

[32] R. Yerushalmi, M.E. van der Boom, H. Cohen, J. Phys. Chem. C 111 (2007) 13652.

[33] H. Cohen, Nano Lett. 9 (2009) 2327.

[34] H. Shpaisman, E. Salomon, G. Nesher, A. Vilan, H. Cohen, A. Kahn, D. Cahen, J. Phys. Chem. C 113 (2009) 3313.

[35] T. Aqua, H. Cohen, O. Sinaim, V. Frydman, T. Bendikov, D. Krepel, O. Hod, L. Kronikm, R. Naaman, J. Phys. Chem. C 115 (2011) 24888.

[36] Y. Itzhaik, G. Hodes, H. Cohen, J. Phys. Chem. Lett. 2 (2011) 2872.

[37] U.K. Demirok, G. Ertas, S. Suzer, J. Phys. Chem. B 108 (2004) 5179.

[38] G. Ertas, U.K. Demirok, A. Atalar, S. Suzer, Appl. Phys. Lett. 86 (2005) 183110.

[39] H. Sezen, G. Ertas, A. Dana, S. Suzer, Macromolecules 40 (2007) 4109.

[40] S. Suzer, H. Sezen, A. Dana, Anal. Chem. 80 (2008) 3931.

[41] H. Sezen, G. Ertas, S. Suzer, J. Electron. Spectrosc. Relat. Phenom. 178-179 (2010) 373.

[42] H. Sezen, S. Suzer, Surf. Sci. Lett. 604 (2010) L159.

[43] H. Sezen, E. Ozbay, O. Aktas, S. Suzer, Appl. Phys. Lett. 98 (2011) 111901

[44] E. Yilmaz, S. Suzer, Appl. Surf. Sci. 256 (2010) 6630.

[45] H. Sezen, S. Suzer, J. Chem. Phys. 135 (2011) 141102.

[46] H. Sezen, S. Suzer, J. Spectrosc. Dyn. 2 (2012) 1.

[47] H. Sezen, A.A. Rockett, S. Suzer, Anal. Chem. 84 (2012) 2990

[48] M.W. Majeski, F.D. Pleticha, I.L. Bolotin, L. Hanley, E. Yilmaz, S. Suzer, J. Vac. Sci. Technol., A 30 (2012) 04D109.

[49] E. Yilmaz, H. Sezen, S. Suzer, Angew. Chem. Int. Ed. 51 (2012) 5488.

[50] S. Suzer, Anal. Methods 4 (2012) 3527.

[51] J.D. Plummer, M.D. Deal, P.B. Griffin, Silicon VLSI Technology: Fundamentals, Practice and Modeling, Prentice Hall Upper Saddle River, New Jersey, 2000.

[52] A.J. Bard, L.R. Faulkner, Electrochemical Methods, Fundamentals and Applications, 2nd ed. Wiley, 2001.

[53] M. Copuroglu, H. Sezen, R.L. Opila, S. Suzer, (in preparation).

[54] N.J. Halas, J. Bokor, Phys. Rev. Lett. 62 (1989) 1679.

[55] J.P. Long, H.R. Sadeghi, J.C. Rife, M.N. Kabler, Phys. Rev. Lett. 64 (1990) 1158.

[56] M. Marsi, R. Belkhou, C. Grupp, G. Panaccione, A. Taleb-Ibrahimi, L. Nahon, D. Garzella, D. Nutarelli, E. Renault, R. Roux, M.E. Couprie, M. Billardon, Phys. Rev. B 61 (2000) R5070.

[57] W. Widdra, D. Brocker, T. Giessel, I.V. Hertel, W. Kruger, A. Liero, F. Noack, V. Petrov, D. Pop, P.M. Schmidt, R. Weber, I. Will, B. Winter, Surf. Sci. 543 (2003) 87.

[58] D. Brocker, T. Giessel, W. Widdra, Chem. Phys. 299 (2004) 247.

[59] S. Suzer (unpublished).

[60] S. Iwata, A. Ishizaka, J. Appl. Phys. 79 (1996) 6653.

[61] J.F. Moulder, W.F. Stickle, P.E. Sobol, Handbook of X-Ray Photoelectron Spectroscopy, Physical Electronics Division, Perkin-Elmer Corp, Minnesota, 1992.

[62] A.W. Adamson, Physical Chemistry of Surfaces, 5th ed. Wiley, 1990. 